\title{
MANIPULAÇÃO DAS PREFERÊNCIAS DE CONSUMO: ALIENAÇÃ̃O HUMANA E DEGRADAÇÃO AMBIENTAL NOS CAMINHOS DE UM MODELO SOCIAL INSUSTENTÁVEL
}

\author{
MANIPULATION OF CONSUMER PREFERENCES: HUMAN ALIENATION \\ AND ENVIRONMENTAL DETERIORATION IN THE WAYS OF A SOCIAL \\ MODEL UNTENABLE
}

\author{
${ }^{1}$ Marcio Mamede Bastos de Carvalho
}

\section{RESUMO}

Este trabalho tem por objetivo a análise das teorias do fetichismo da mercadoria desenvolvida por Karl Marx e do fetichismo da subjetividade de Zygmunt Bauman, na substituição das relações entre pessoas por objetos, a alienação daquelas e a degradação do meio ambiente natural através de mecanismos de manipulação decorrentes do Capitalismo Mundial Integrado. Também será analisada a influência da publicidade voltada ao consumo conspícuo e suas manobras na modulação de subjetividades individuais e coletivas, afastando o homem e o meio de suas essências para converter ambos em objetos mercantis. Para tanto, adentraremos na análise do capitalismo moderno e suas ferramentas midiáticas em escala global na alienação humana e do meio ambiente natural, num modelo de organização social cada vez mais insustentável.

Palavras-chave: Fetichismo, Capitalismo, Publicidade, Consumismo, Alienação humana e ambiental

\begin{abstract}
This work aims at the study and analysis of theories of "commodity fetishism" developed by Karl Marx and the "fetishism of subjectivity" of Zygmunt Bauman, the substitution of relations between people and objects for disposal and those of the natural environment through manipulation mechanisms arising from Capitalism Control. Will also be analyzed the difference between consumption and consumerism and whether and to what extent the latter via modulation of individual and social subjectivities away the man of your being and converts it to object. To do so, joining analysis of modern capitalism and its media tools on a global scale in human alienation and the natural environment.
\end{abstract}

Keywords: Fetishism, Capitalism, Advertising, Consumerism, Environmental and human alienation

\footnotetext{
${ }^{1}$ Mestre em Direito pelo Universidade de Caxias do Sul - UCS, Rio Grande do Sul (Brasil). Sócio pelo Mamede \& Tartari Advogados - M \& T ADVOGADOS (Brasil). E-mail: marcio.mamede@ hotmail.com
} 


\section{INTRODUÇÃO}

O consumo sempre foi uma necessidade inerente aos seres vivos. Não é diferente com os seres humanos que necessitam consumir para se desenvolverem, ampliarem a expectativa e a qualidade de vida.

Há, portanto, que se distinguir entre consumo e consumo conspícuo, sobretudo pelo fato desta última modalidade ter conduzido à alienação dos indivíduos e à degradação do meio ambiente natural num modelo de organização sócio-econômica cada vez mais insustentável para ambos.

A perspectiva metodológica aqui adotada tem duas dimensões: uma é a analítica descritiva a partir de categorias de pensamento de autores como Marx, Bauman, Deleuze, Guattari e Lukács entre outros; a outra é a crítica.

Quanto ao plano de exposição, inicialmente põem-se em foco o "fetichismo da mercadoria" de Karl Marx e o "fetichismo da subjetividade" de Zygmunt Bauman, para a compreensão da relação entre homens obscurecida pela relação entre mercadorias e símbolos e no que consistem tais feitiços como estruturadores da construção da subjetividade humana voltada para o consumismo de modos de ser e mercadorias.

Num segundo momento analisaremos as diferenças entre consumo e consumismo, nos utilizando de contextos sociais diversos (modernidade e contemporaneidade) a partir das "necessidades" criadas pelo modelo de produção capitalista tradicional e contemporâneo.

$\mathrm{Na}$ terceira parte será analisado em que medida o momento de organização social atual num cenário globalizado e globalizante, bem como o discurso publicitário têm servido como ferramenta na criação de indivíduos e coletividades sedentas pelo consumismo nestas sociedades cada vez mais comodificadas. Sobretudo, como, neste arranjo social, tudo se torna unificado e difuso e as instituições permeadas pelo capital reciclam as vontades e desejos humanos rotineiros, se valendo de informações da própria sociedade, bem como de instituições outrora não dominadas pelo mercado - escola, mídia, família - para manipular as preferências de consumo.

Por fim, a partir dos escritos de Marx, acerca da alienação, e Lukács, através do fenômeno da reificação, discute-se como num modelo econômico capitalista cada vez mais mundial e integrado, numa Sociedade de Consumo (segundo Bauman), o consumismo tem afastado o homem de sua identidade e degradado o meio ambiente, objetivando ambos. 


\section{O "FETICHISMO DA MERCADORIA" E O "FETICHISMO DA SUBJETIVIDADE" SEGUNDO MARX E BAUMAN}

O termo "fetiche" tem sua origem no termo latim facticius, que significa artificial ou fictício, que por sua vez deram origem ao termo em francês fétiche e em português feitiço. Em sua origem e nas conotações francesa ou portuguesa o "fetiche" tem como idéia um objeto material ao qual eram atribuídos poderes, negativos ou positivos, mágicos ou sobrenaturais, termo que se referia a objetos utilizados principalmente em cultos religiosos.

O "fetiche" tornou-se conhecido, em 1757, sobretudo na Europa através do erudito francês Charles de Brosses, mas foi Karl Marx (2002) que, ao tratar as relações sociais do modelo de economia capitalista de produção na Europa do século XIX, quem desenvolveu uma teoria acerca do fetiche, ou fetichismo.

Marx descreve o caráter misterioso que o trabalho apresenta, na "sociedade de produtores", ao ganhar a forma de mercadoria, o valor que estas adquirem e as relações entre o trabalho e seu produto - a mercadoria.

Para Marx o "fetichismo da mercadoria" tem como elemento fundamental demonstrar, na economia capitalista, a relação social entre pessoas mediatizada por coisas.

Ao estudar este fenômeno, Marx ressalta que o "caráter misterioso da mercadoria não provém do seu valor-de-uso, nem tampouco dos fatores determinantes do valor" (2002, p. 93).

Determinado objeto pode ser valor-de-uso sem ser valor, e este último pode ser mensurado pela quantidade de trabalho empregado para produzir o objeto. Entretanto, na sociedade de produtores a mercadoria apresenta dupla feição (valor-de-uso e valor-de-troca), enquanto o trabalho humano não apresenta mais as mesmas características que lhe pertenciam como gerador de valores de uso.

Mesmo que o valor de determinada mercadoria esteja para o valor de qualquer outra em relação com o tempo de trabalho necessário à produção desta ou daquela, pela teoria do "fetichismo da mercadoria" não há mais relação física entre coisas físicas. A relação entre homens assume a forma de relação entre coisas por estes produzidas o que faz crer que as mercadorias assumem vida própria e estão alheias às atividades do homem.

Pela teoria desenvolvida por Marx (2002) o valor atribuído para as mercadorias tenta justificar-se em bases objetivas, quando é o trabalho humano dispendido para transformar a natureza em mercadoria que se mostra objetivo, sendo o valor atribuído àquela abstrato ao trabalho que a produziu. 
Salienta Marx (2002, pp. 62) que: "a forma mercadoria e a relação de valor entre os produtos do trabalho, a qual caracteriza esta forma, nada tem a ver com a natureza física destes produtos nem com as relações materiais dela decorrentes".

Para uma melhor compreensão da teoria do "fetichismo da mercadoria" importante se faz referir que o fetichismo deve ser entendido como a essência de todo o modelo econômico capitalista analisado por Marx na "sociedade de produtores", abrangendo não só a mercadoria, mas o fetichismo do valor (preço), o dinheiro e o trabalho, sendo importante analisarmos aqui, mesmo que de forma sucinta, estes elementos.

$\mathrm{O}$ preço pode ser aqui considerado como a expressão monetária do valor. $\mathrm{Na}$ sociedade capitalista de produção, determinada pelo mercado econômico, os objetos de uso são individualmente produzidos pelo trabalho privado e em seu todo pelo trabalho social e se fetichizam constituindo relações do tipo homem-mercadoria-homem, nas quais é o mercado que estabelece os preços.

O dinheiro, no sistema de mercado, converte-se em mercadoria e esta naquele. Neste círculo, cada produto individual do trabalho precisa ser transformado em dinheiro para em seguida se transformar em mercadoria, o que torna ainda mais difícil resgatar o trabalho humano como valor-de-uso, já que obscurecido pelo manto do dinheiro que encobre o valor do trabalho concreto.

Já o trabalho, na sociedade de produtores adquire dupla feição, podendo ser distinguido entre trabalho concreto (quantidade de horas trabalhadas para a produção de dada mercadoria, com suas especificidades em cada ramo e habilidades individuais existentes) e trabalho abstrato (considerados meramente como dispêndio de energia física e mental humanas), não estando ao alcance do produtor isolado determinar o valor atribuído à mercadoria, já que incumbe ao mercado este papel. Também compete ao mercado a determinação do número de horas que vale um determinado objeto, traduzindo a relação social em uma relação homemmercadoria-homem.

Assim, as relações sociais de trabalho entre os homens, na "sociedade de produtores", fica obscurecida pela aparência de relações entre coisas, bem como na forma de atribuição de valor a estas últimas, constituindo uma manobra fundamental do mercado econômico, consoante se deflui da seguinte passagem da obra do sociólogo alemão:

A determinação da quantidade do valor pelo tempo de trabalho é, por isso, um segredo oculto sob os movimentos visíveis dos valores relativos das mercadorias. Sua descoberta destrói a aparência de causalidade que reveste a determinação das quantidades de valor dos produtos do trabalho, mas não suprime a forma material dessa determinação. (Marx, 2002, p. 97) 
Tais relações tem razão de ser na "sociedade de produtores", sobretudo de alienar o homem do produto de seu trabalho, no qual o processo de produção domina o homem e não o contrário, numa relação social obscurecida pelo fetichismo - o totem da mercadoria se sobrepõe ao homem, como o são as pré-determinações religiosas.

Deve ser ressaltado que ao desenvolver a teoria do "fetiche da mercadoria" Marx tinha como objeto de estudo as classes sociais do século XIX, sobretudo as relações entre os detentores do capital e a classe operária, bem como a ação daquela de ignorar, ou tentar esconder, as iterações humanas por traz do movimento de produção e circulação das mercadorias, como se estas estabelecessem relações entre si sem a mediação do homem.

As lições de Marx são de suma importância sobretudo para o estudo da sociedade atual, em especial à análise da "sociedade de consumidores" e o "fetichismo da subjetividade" que visa ocultar a realidade comodificada desta sociedade.

Assim como na "sociedade de produtores" a mercadoria ganha características sobre humanas, como se não tivessem origem na ação do homem, sendo, inclusive, a força de trabalho convertida a este status, na "sociedade de consumidores" é a vez de comprar e vender os símbolos empregados na construção da identidade humana (Bauman, 2008, p. 23).

Para adentrarmos no tema do "fetiche da subjetividade", necessária se faz a análise desta última expressão.

Pois bem, de modo sucinto, por subjetividade entenda-se o mundo interno do ser humano, mundo este composto de emoções, sentimentos e pensamentos baseados nas percepções do indivíduo, as quais configuram subestruturas da personalidade.

González Rey (1997, p. 107) sustenta que a subjetividade estaria organizada por processos e configurações que se inter-relacionam de forma permanente e que estão em constante desenvolvimento e vinculados à inserção simultânea do sujeito em outro sistema igualmente complexo - a sociedade.

Não se quer aqui afirmar que tenha havido uma drástica ruptura do tecido social, com a substituição da "sociedade de produtores" por uma "sociedade de consumidores". Esta última começou a ser gestada naquela e, atualmente, ganhou os contornos conforme a concebemos atualmente. ${ }^{1}$

\footnotetext{
${ }^{1}$ Conforme descrição de Bauman: "No seu atual estágio final moderno (Giddens), segundo estágio moderno (Beck), supramoderno (Balandier) ou pós-moderno, a sociedade (...) precisa engajar seus membros pela condição de consumidores. A maneira como a sociedade atual molda seus membros é ditada, primeiro e acima de tudo, pelo dever de desempenhar o papel de consumidor. A norma que nossa sociedade coloca para seus membros é a da capacidade e vontade de desempenhar esse papel" (BAUMAN, Zygmunt. Globalização: as conseqüências humanas. Rio de Janeiro: Jorge Zahar. 1999. p. 87-88)
} 
Neste novo contexto, o social se subjetiva para converter-se em algo relevante para o desenvolvimento do indivíduo, assim como o subjetivo permanentemente se objetiva ao converter-se em parte da realidade social, com o qual se redefine constantemente como processo cultural (González Rey, 1997, p. 108).

Nessa linha de raciocínio (González Rey, 1997, p. 150-151), a realidade pode ser entendida como a conjugação de bases subjetivas - expressão do campo de valores que a interpreta - e bases objetivas - desenvolvimento concreto das forças produtivas e iteração social. A realidade é constantemente elaborada, seja em suas bases materiais, seja em suas bases valorativas. E o indivíduo é o sujeito singular desta dinâmica, podendo ser agente ativo da transformação social tendo ou não consciência dos fatos, ou, como acontece na maioria das vezes, receber prontas as bases materiais (colocadas pelas instituições) e os valores (bases para a socialização).

A subjetividade, portanto, é formada pelo eu interno e sua iteração com o exterior humano. No entanto, a atividade concreta exercida pelo sujeito visa inseri-lo num campo objetivo da sociedade (trabalho, relação de classe, consumo, etc) agindo no plano individual de acordo com essa demanda social objetiva.

$\mathrm{Na}$ atualidade o consumismo se tornou "cultura", forma de reconhecimento e inserção social, busca incessante de prazer individual. O "ter" se sobrepõe ao "ser" como nuvens impenetráveis das tardes chuvosas de inverno. Os sonhos de fama e dinheiro são os desejos individuais no cenário social.

Para os indivíduos do século XXI "tornar-se uma mercadoria desejável e desejada é a matéria de que são feitos os sonhos e os contos de fadas” (Bauman, 2008, p. 22).

Vivemos numa época em que o aparato produtivo está entrelaçado ao universo simbólico, na qual a cultura é industrializada pelo modelo econômico de produção capitalista. Nas palavras de Jamerson (1996), vivemos numa época em que o capitalismo dominou o inconsciente humano.

No campo da psicanálise, Lacan (2005) alargou a discussão acerca do fetichismo e suas relações com o objeto ao ponto do próprio fetichismo ser tido como elemento estruturador da subjetividade.

Bauman ao comparar o "fetiche da mercadoria" com o "fetiche da subjetividade" sustenta que este último, na "sociedade de consumidores", também tem o papel de tornar imperceptível a real relação entre pessoas obscurecida pela representação dos símbolos.

No caso a subjetividade na sociedade de consumidores, é a vez de comprar e vender os símbolos empregados na construção da identidade - a expressão 
supostamente pública do "self" que na verdade é o "simulacro" de Jean Baudrillard, colocado a "representação" no lugar daquilo que ela deveria representar -, a serem eliminados da aparência do produto final. (Bauman, 2008 , p. 22)

Esse modo de agir do indivíduo, inconscientemente ou não, de absorver símbolos, códigos e condições materiais para que possam ser qualificados, coloca-os num mercado simbólico de trocas, não entre bens, mas entre pessoas convertidas em mercadorias.

O "fetichismo da subjetividade", na sociedade de consumidores, traduz a discussão acerca da dissolução daquilo que não mais se separa - o sujeito e o objeto, o consumidor e a mercadoria.

Em que pesem as teorias do "fetichismo da mercadoria" e do "fetichismo da subjetividade" terem sido desenvolvidas em momentos diversos, tentam descrever a ilusão criada para encobertar as relações humanas por traz das relações entre objetos.

Observadas de forma breve estas duas teorias, passaremos a seguir à análise das formas de consumo da atualidade social.

\section{O CONSUMISMO COMO UM DEVER SOCIAL}

Sob a perspectiva do desenvolvimento humano básico, os insumos de consumo podem ser divididos em bens e serviços, que podem cumprir ou não funções acerca das necessidades humanas.

Os elementos de consumo podem servir para atender as necessidades básicas dos seres humanos, como por exemplo, água, alimentação, saúde, educação, vestuário, acesso à informação, lazer, transporte ou como ferramenta de "felicidade" individual, satisfação, “bem-estar”, prazer ou inserção social.

Consumir é algo inerente a todos os seres vivos, sendo que, se analisarmos apenas o aspecto biológico do consumo, mesmo no paleolítico os homens já se utilizavam do meio ambiente natural para extrair, armazenar, trocar e consumir os elementos disponíveis.

Não podemos aqui tecer uma linha divisória temporal entre consumo e consumismo humano, sob pena de negarmos a historicidade da evolução desta espécie, sua capacidade de desenvolvimento e criatividade. Porém, é a partir de alguns fenômenos, dentre eles o industrialismo, o capitalismo e a globalização, que o consumo adquire uma nova roupagem e seus níveis se ampliam de forma conspícua. 
$\mathrm{Na}$ "pós-modernidade"2 não consumimos para sobrevivermos, mas "somos conduzidos" a vivermos para consumir. Nesta esteira o consumismo se tornou o verdadeiro propósito da existência humana.

O consumo se baseia em necessidades primordiais para o homem e para a sociedade na qual ele está inserido. Diferente do consumismo, que pode se traduzir no ato, ou hábito, de adquiri produtos, em sua maioria supérfluos, de maneira muitas vezes compulsiva, sem que haja a necessidade real de adquiri-los, ou que os objetos sejam imprescindíveis à manutenção e desenvolvimento humano.

Este fenômeno, ou conjunto de fenômenos, afasta os consumidores da busca das necessidades práticas e os aproxima de pautas de consumo que visam inserção e reconhecimento social, satisfação, prazer e "bem-estar" individual.

A partir do século XX a "sociedade de produtores", que buscava no consumo a satisfação de desejos humanos de segurança e sonhos de estabilidade, é substituída pela "sociedade de consumidores", que associa o consumismo não à busca de satisfação de necessidades básicas e segurança, "mas a um volume e uma intensidade de desejos sempre crescente" (Bauman, 2008, p. 44) e urgentes, o que implica no uso imediato do objeto de consumo, o descarte também rápido deste e a busca de outros objetos para satisfação ou bemestar.

Os modelos de consumo vividos nas sociedades pré-modernas encontram traços comuns - busca de satisfação de necessidades típicas. Diferentemente, os modelos de consumo vivenciados na atualidade sofrem significativa alteração na dinâmica do modo de vida humano de ser e conviver em sociedade.

Pode-se afirmar que esta forma de ser e agir humano, tido como consumismo ${ }^{3}$, sofreu e sofre forte influência da industrialização dos meios de produção e do modelo de produção capitalista atual. Maior produção conduz a maior consumo. Quanto mais se produz, mas se buscam mercados para consumir.

${ }^{2}$ Utilizaremos apenas o termo "Modernidade", para nos referirmos à forma de vida, costume e organização social que surgiram na Europa a partir do século XVII e que tiveram influência em escala global. Bauman defende estarmos inseridos num período de "Modernidade Líquida" (BAUMAN, Zygmunt. Modernidade líquida. Rio de Janeiro: Jorge Zahar Ed., 2001). Giddens (GIDDENS, Anthony. As conseqüências da modernidade. Trad. Raul Fiker. São Paulo: UNESP. 1991. p. 8) descreve a contemporaneidade como uma modernidade radicalizada, fazendo distinção entre esta e a pós-modernidade.

3 Aqui a rotulação "consumismo", que pode ser substituída por "sociedade de consumidores" ou "cultura de consumo", ou "hiperconsumo" é o que Max Weber chama de "tipos ideais" que se traduzem em "abstrações que tentam apreender a singularidade de uma configuração composta de ingredientes que não são absolutamente singulares, e que separam os padrões definidores dessa figuração da multiplicidade de aspectos que a configuração em questão compartilha com outras", para descrever aspectos da realidade social. (BAUMAN, 2008, p. 39). 
Segundo Perkin (In CAMPBELL, 2001. p. 32) “[...] a procura do consumidor foi a chave decisiva para a Revolução Industrial". Portanto a busca por mercados de consumo se mostrou fundamental para a Revolução Industrial e não apenas o processo de industrialização foi de suma importância para esta nova forma de agir da sociedade.

A Revolução Industrial, iniciada na Inglaterra no Século XVII, aliada ao capitalismo, portanto, pode ser tida como o marco para o aparecimento da base econômica das sociedades modernas, dentre estas a "sociedade de consumo".

Neste ciclo entre produção acelerada e necessidade de mercados de consumo - ou "consumismo" - acelerado, a busca de satisfação individual e inserção social deixa rastros de exclusão social e desigualdade.

Para consumir é necessário ter dinheiro. Para ter dinheiro, com exceções, é necessário vender a força de trabalho e para consumir mais é necessário trabalhar mais e ganhar mais dinheiro. Por sua vez, o dinheiro pode ser adquirido pela venda da força de trabalho ou, no caso da classe detentora dos meios de produção, pela exploração da força de trabalho de terceiros.

Esta forma consumista de convívio e inserção social tem como elemento a ascensão na escada das classes ${ }^{4}$ sociais e a busca de prazeres individuais e reconhecimento social. No que diz respeito àquele elemento - inserção social - o indivíduo busca se espelhar em outros indivíduos que se encontram num degrau mais elevado de poder de consumo e, caso consiga subir este degrau, busca atingir o próximo e assim sucessivamente para alcançar reconhecimento social e "bem- estar".

Para ilustrar este fenômeno social, Veblen (1985, p. 55) nos remete à idéia de emulação, pela qual as camadas sociais mais pobres buscam se espelhar nas camadas mais ricas - no caso descrito pelo autor, a "classe ociosa" - por estas estarem, na sociedade industrial, no topo da estrutura social em termos de riqueza, reconhecimento e poder de consumo.

Para Veblen a "classe ociosa" surgiu juntamente com a propriedade privada e a acumulação de riquezas que permitia a esta classe não trabalhar e consumir itens tidos como supérfluos.

\footnotetext{
${ }^{4}$ Weber salienta que "situação de classe, que podemos expressar mais sucintamente como a oportunidade típica de uma oferta de bens, de condições de vida exteriores e experiências pessoais de vida, e na medida em que essa oportunidade é determinada pelo volume e tipo de poder, ou falta deles, de dispor de bens ou habilidades em benefício de renda de uma determinada ordem econômica. A palavra classe refere-se a qualquer grupo de pessoas que se encontram na mesma situação de classe”. (WEBER, Max. Classe, estamento, partido. In: GERTH, Hans e MILLS, Wright (Org.). Max Weber - Ensaios de sociologia. Rio de Janeiro: Zahar Editores, 1974, p. 212.)
} 
Campbell, ao tratar o fenômeno do consumo no século XVII ilustra o crescimento da produção e consumo de mercadorias de "luxo":

Ao contrário da impressão mais comum, as indústrias de manufaturados mais estreitamente associadas ao início da Revolução Industrial eram as que produziam mais bens de consumo do que de capital e, entre elas, as que produziam objetos para consumo de "luxo" predominavam (...) a nova procura era de fato de tudo o que não era necessidade. (2001, p. 42)

Na sociedade contemporânea, o consumismo, pode-se dizer, torna-se um arranjo social advindo da reciclagem das vontades e desejos humanos rotineiros, que abarca todas as classes sociais.

$\mathrm{O}$ ato de adquirir algo necessário para sua subsistência é um tipo de consumo utópico para a sociedade atual, face a constante influência da mídia e da maciça publicidade para realização de desejos alheios às necessidades básicas humanas. Não basta adquirir os bens necessários às necessidades básicas (consumo), mas adquirir itens que se mostrem importantes não apenas aos olhos de quem os consome, mas também aos olhos dos outros sujeitos sociais (consumismo).

Atualmente, mesmo que diante de um contexto histórico-temporal diverso, mas sob a influência de hábitos surgidos no século XVII, o consumismo é um atributo da sociedade, exercendo maior influência, sobretudo, nas sociedades ocidentais.

Bauman (1999) sustenta que a sociedade contemporânea pode ser entendida como uma "sociedade de consumo", enquanto na sua fase fundadora (ou industrial) consistia em uma "sociedade de produtores". Ou seja, naquela sociedade o consumo passa a ser não um direito ou a satisfação de um prazer, mas um dever social.

Nesta etapa histórica, a opção pelo consumismo parece estar alheia a decisão do indivíduo, cabendo a este apenas optar pela aquisição dos bens colocados à disposição pelo mercado econômico capitalista, como forma de inserção social e "prazer" individual.

Ora, se não possuo uma conta nas "redes sociais" sou invisível, se não possuo um telefone celular sou incomunicável e se não possuo dinheiro sou um transtorno para a sociedade.

Os sonhos são moldados e postos à venda. Mas se não temos dinheiro agora para a aquisição do próximo sonho não precisamos nos preocupar, pois as "instituições disciplinares" $" 5$ dão um jeito, dividindo o pagamento em quantas prestações o cartão de crédito

\footnotetext{
${ }^{5}$ Como instituições disciplinares entendam-se aquelas que ditam as regras que somos, conscientemente ou não, levados a seguir.
} 
possa suportar. Entretanto, antes mesmo de quitarmos os débitos deste sonho, outros sonhos surgirão e nos endividamos para sua aquisição.

Conforme afirma Sibilia (2002, p. 37), o modo de organização da "sociedade de consumo" aprisiona o consumidor num status de devedor perpétuo.

Há também um paradoxo social neste modo de organização voltada ao consumo conspícuo de símbolos e mercadorias, uma vez que a maior parte da população não possui sequer acesso aos recursos básicos para manutenção de sua subsistência.

Este novo modo de ser/agir da sociedade contemporânea encontra relevantes subsídios na globalização e na massiva publicidade dos meios de comunicação. Elementos estes que trataremos a seguir, sem termos a pretensão de esgotá-los, mas com o fim de melhor elucidarmos o fenômeno do consumismo e suas conseqüências para o homem e o meio ambiente.

\section{MODERNIDADE GLOBALIZANTE E PUBLICIDADE}

A modernidade, seja em sua concepção líquida ${ }^{6}$ ou radicalizada $^{7}$, é eminentemente globalizante e pode ser compreendida como a forma de vida, costume e organização social que surgiram na Europa a partir do século XVII e que tiveram influência em escala global, sobretudo para as organizações sociais atuais. Ela também é multidimensional e dinâmica.

É a modernidade multidimensional, pois cada um de seus elementos no âmbito das suas instituições representam algum papel na organização e desenvolvimento das atividades humanas e há interconexões entre as relações sociais. É globalizante, pois há uma intensificação das relações sociais em escala mundial que ligam localidades distantes por eventos ocorridos no âmbito local e modelados globalmente. E é dinâmica ao promover uma separação entre tempo e espaço.

Tal separação tempo-espaço para Giddens (1991) promove um desencaixe dos sistemas sociais, o que, a grosso modo, se traduz no deslocamento das relações sociais de contextos locais de interação e sua reestruturação sobre tempo-espaço indefinidos. Desencaixe este que é permitido por instrumentos de confiança inerentes ao desenvolvimento das

\footnotetext{
${ }^{6}$ Sobre o conceito de modernidade líquida ver BAUMAN, Zygmunt. Modernidade líquida. Rio de Janeiro: Jorge Zahar Ed., 2001.

${ }^{7}$ Para maior aprofundamento das características da modernidade radicalizada, ver GIDDENS, Anthony. As consequiências da modernidade. Trad. Raul Fiker. São Paulo: UNESP. 1991.
} 
instituições sociais modernas, podendo aqui obter destaque às fichas simbólicas - como, por exemplo, o dinheiro - e aos sistemas peritos - o autor caracteriza estes como sendo sistemas de competência profissional ou conhecimento técnico desenvolvidos por experts que levam à "fé” (confiança) no conhecimento aplicado.

Tais mecanismos de desencaixe - ou separação -, aliados à confiança, podem conduzir à remoção das relações sociais das imediações do contexto tempo-espaço. Melhor explicando, o estudo de acontecimentos num determinado local influencia e é influenciado por acontecimentos ocorridos em locais distantes daquele.

As consequiências da modernidade inserem o indivíduo ou as coletividades numa sensação de desorientação quanto aos eventos sociais e o controle de nossos destinos.

Pode-se dizer que a modernidade retira o autor social do amparo tradicional de sua pequena comunidade e o submete a influência de organizações muito maiores e impessoais que atuam em escala global.

As instituições sociais modernas (e pós-modernas) se mostram únicas e se diferem amplamente das instituições sociais tradicionais, ou pré-modernos, tendo como um dos seus elementos fundamentais a globalização.

Conceituar globalização ${ }^{8}$ não é tarefa das mais fáceis, já que este fenômeno além de não ser atual, guarda distintas definições que dependem do enfoque de estudo (econômico, financeiro, social, político, jurídico, cultural, etc). Sendo assim, para tratarmos este tema, sem alongadas discussões conceituais, nos utilizaremos do fenômeno da globalização em suas dimensões econômica capitalista mundial e social.

Nestas dimensões, sobretudo no ocidente, a organização econômica mundial é dominada pelos mecanismos do sistema capitalistas que se sobrepõem inclusive a política. Sendo assim, as autonomias dos Estados, sobretudo no aspecto econômico, são relativizadas pelo poder das instituições capitalistas e as políticas de mercado regidas por estas.

Diante deste cenário globalizante, a industrialização e centralização dos meios de produção disseminam nos cantos mais remotos do planeta seus maquinários e tecnologias. Nem mesmo os Estados cuja economia é/era primordialmente agrícola ficam à margem das influências da indústria capitalista atual. A produção mecanizada de sementes modificadas geneticamente já é uma realidade mundial.

\footnotetext{
${ }^{8} \mathrm{Na}$ dimensão econômica, Faria conceitua a globalização como sendo a "transnacionalização dos mercados de insumos, produção, capitais, finanças e consumo" (FARIA, José Eduardo. $O$ direito na economia globalizada. São Paulo: Malheiros, 1999, p. 13), já Dupas descreve o fenômeno como sendo a "intensificação do processo de internacionalização das economias capitalistas" (DUPAS, Gilberto. Economia global e exclusão social: pobreza, emprego, estado e o futuro do capitalismo. São Paulo: Paz e Terra, 1999, p. 14).
} 
O capitalismo não tem nação, ele estará em todo e qualquer lugar onde a equação entre força de trabalho, matéria prima, produção e comercialização obtenha o resultado mais valia, alterando substancialmente as relações preexistentes entre a organização social humana e o meio ambiente.

Estamos todos sujeitos aos efeitos das "forças anônimas" da globalização, suas facetas econômicas e perspectivas ${ }^{9}$ de igualdade de oportunidades e bem estar social.

A "globalização" não diz respeito ao que todos nós, ou pelo menos os mais talentosos e empreendedores, desejamos ou esperamos fazer. Diz respeito ao que está acontecendo a todos nós. A idéia de "globalização" refere-se explicitamente às "forças anônimas" de von Wright operando na vasta "terra de ninguém" - nebulosa e lamacenta, intransitável e indomável — que se estende para além do alcance da capacidade de desígnio e ação de quem quer que seja em particular. (Bauman, 1999, p. 59)

E cumpre aqui lembrar que na sociedade atual - "sociedade de consumidores" - o consumismo, pode-se dizer, torna-se um arranjo social advindo da reciclagem das vontades e desejos humanos rotineiros. Neste arranjo social globalizado tudo é unificado e difuso. ${ }^{10}$

Vendemos nossa força de trabalho e nosso self para tentarmos alcançar bem estar social e satisfação pessoal, adquirimos mercadorias e símbolos que nos tornam mercadorias desejáveis na proporção que o salário ou o cartão de crédito possam parcelar. Mas as sensações de satisfação e bem estar duram até a próxima propaganda da TV, que nos alertam que nossos sonhos se tornaram obsoletos. O sonho de consumo agora é outro - a roupa da "nova" moda, a televisão 3D, o smartphone moderno, o carro do ano, etc. E o discurso publicitário, neste cenário de economia capitalista mundial, tem importância fundamental na modulação dos "sonhos" de consumo.

Para adentrarmos na análise da publicidade, inicialmente, faz-se importante definirmos seu conceito e forma pela qual se apresenta ao público alvo no cenário social contemporâneo. Pois bem, a fim de melhor situar o leitor, podemos conceituar publicidade como sendo a mensagem veiculada nos meios de comunicação com o objetivo de informar e/ou persuadir seu interlocutor, através de aspectos racionais e emocionais da linguagem, acerca de determinado acontecimento, produto ou serviço.

\footnotetext{
${ }^{9}$ Bauman sustenta que: “A mentira da promessa do livre comércio é bem encoberta; a conexão entre a crescente miséria e desespero dos muitos 'imobilizados' e as novas liberdades dos poucos com mobilidade é difícil de perceber nos informes sobre as regiões lançadas na ponta sofredora da 'globalização'. (BAUMAN, Zygmunt. Globalização: as conseqüências humanas; tradução Marcus Penchel. Rio de Janeiro: Jorge Zahar Ed., 1999. p. 69)

${ }^{10}$ Estas sensações de sofrimento e bem estar da sociedade humana tem como precedente, amarras, que são facilmente retraçadas e remodeladas pela globalização e pelo sistema de produção capitalista.
} 
Nas sociedades contemporâneas, o acesso dos agentes a informações geradas em contextos globais, e iteração entre acontecimentos regionais e aqueles, pode ser marcada pela justaposição de acontecimentos (locais ou não) no cotidiano social, sendo a(s) mídia(s) um dos principais alicerces na alteração das condições espaço-temporais e no processo de construção social da realidade, promovendo um significativo aumento da experiência social mediada pela “informação" e não apenas pela percepção das experiências físicas dos acontecimentos.

Neste contexto, as mídias possuem papel decisivo nos processos de construção social da realidade, em praticamente todas as dimensões da vida humana, seja na esfera da política, da religião, do consumo ou do entretenimento. Na grande maioria das vezes são os meios de comunicação que nos apresentam os "fatos" ocorridos em nossa sociedade e no planeta em que vivemos. ${ }^{11}$

E dentre as mídias, a TV se tornou o principal palco de tematização da realidade e de questões fundamentais da vida humana, corporificando o princípio da realidade nas sociedades contemporâneas, atuando de forma destacada na formação do reconhecimento social de políticas, valores, hábitos, dentre outros.

Aqui, o ponto central não está na mídia em si, mas na ótica do discurso por esta utilizada na "informação" e manipulação dos indivíduos e coletividades, pelo poder que possuem na construção social da realidade. ${ }^{12}$

É nesta perspectiva que o discurso publicitário cumpre seu papel ao utilizar recursos da linguagem, em suas linhas e entrelinhas, para impor mitos, valores, ideais e outras figuras simbólicas na formação de desejos e subjetividades. Tendo como objetivo central a venda de um determinado serviço ou produto, sob a ótica de símbolos (marcas) visando o consumo repetitivo de objetos, valores, sujeitos, prazeres, dentre outros que o dinheiro possa pagar.

Para tanto, o discurso publicitário se apodera de diversos elementos - a prática social, a produção, a distribuição, a psicologia, o consumo, o fetiche, a sedução - para atingir o senso comum e tornar seus produtos “essenciais" aos consumidores, padronizando o imaginário do consumidor com uma visão de mundo carregada de poder e ideologia ${ }^{13}$.

\footnotetext{
${ }^{11}$ Ver LUHMANN, Niklas. A realidade dos meios de comunicação. São Paulo: Paulus, 2005.

${ }^{12}$ Embora a percepção da realidade pelo sujeito tenha como base a sua autonomia cognitiva, grosso modo, não se pode negar que a percepção de mundo pelos sujeitos, no cenário moderno globalizado e manipulado, leva em consideração também a informação que este recebe diariamente da publicidade veiculada nos principais meios de comunicação.

${ }^{13}$ Fiorin conceitua a ideologia como sendo visões de mundo, apresentadas por discursos próprios e que podem
} 
O discurso publicitário se traduzirá, na maioria das vezes, em expressão da ideologia da classe dominante materializando uma visão de mundo e sublimando a idéia de saber e organização social. E assim, através de sua axiologia de valores (dentre elas o consumismo) organiza a vida social.

A hegemonia do discurso publicitário, por intermédio da manipulação, reproduz a prática social e enfatiza o poder dos símbolos e a influência destes na cultura de consumo, tecendo no imaginário do consumidor a idéia de que a felicidade é um produto que está à venda e que deve ser consumido. As idéias, pessoas, valores, atitudes se transformam em mercadorias vendáveis. Tudo está à venda e deve ser consumido como forma de inclusão social, já que o "senso comum" assim determina, e como forma de se alcançar a felicidade, mas a publicidade também se incumbe de produzir a constante sensação de diferença - diferença que não passam de um sofisma - e infelicidade.

Aqueles que não consomem os produtos "utilitaristas" da moda são vistos como os diferentes, os marginais, os infelizes, só restando a estes uma escolha: consumir para pertencer e para alcançarem a tão sonhada felicidade.

E o capitalismo produz e é reproduzido pelo discurso publicitário de consumismo. Cria, se apropria e remodela as subjetividades. Mercantiliza tudo e todos.

Não se quer aqui afirmar que não haja publicidade que busque a emancipação humana. Mas, sobretudo nas mídias pagas, peço perdão por não me recordar no momento de algum exemplo positivo. Entretanto, quando se trata de publicidade para moldar as preferências de consumo, os exemplos são vastos.

Peço a permissão do leitor para fazer referência aos princípios elencados no artigo 221 da Constituição da República Federativa do Brasil de 1988.

Conforme tal norma fundamental, a produção e programação das emissoras de rádio e televisão deverão se pautar em publicidade que priorize: I - (...) finalidades educativas, artísticas, culturais e informativas; II - promoção da cultura nacional e regional e estímulo à produção independente que objetive sua divulgação; III - regionalização da produção cultural, artística e jornalística, conforme percentuais estabelecidos em lei; IV - respeito aos valores éticos e sociais da pessoa e da família.

No entanto, é só ligarmos a TV para nos depararmos com um tipo diverso de publicidade, que influencia (ou modela) as preferências de consumo, atingindo cada vez mais 
cedo as esferas sociais. Que bombardeia as crianças, criando subjetividades cada vez mais dependentes dos símbolos representados pelas marcas. Que associa o ser ao ter.

E quando falamos de TV, cumpre ressaltar que, na sociedade contemporânea, aquela invadiu todos os lares e se tornou companheira inseparável dos indivíduos, seja na sala, no quarto, no restaurante e até no aparelho celular.

Seja diante do último capítulo da novela ou do jogo de futebol da seleção brasileira, toda nação para enfeitiçada diante da televisão.

Essa ferramenta midiática seria importante na publicidade informativa, educativa e ética, mas está contaminada pela incurável moléstia do capitalismo global, servindo de ferramenta deste modelo econômico na manipulação das preferência de consumo, na alienação humana e degradação do meio ambiente natural.

Acerca destes temas - alienação humana e degradação ambiental - trataremos nas linhas que serão desenvolvidas a seguir.

\section{CONSUMISMO: ALIENAÇÃO HUMANA E DEGRADAÇÃO DO MEIO AMBIENTE}

Nos parágrafos acima tentamos diferenciar consumo de consumismo, bem como trazer à tona a influência que o sistema econômico capitalista contemporâneo, através de suas "artimanhas", dentre estas o fetiche e a publicidade, tem na formação e remodelação do ser e agir da sociedade.

Dedicaremos os próximos parágrafos à análise do consumismo e sua inter-relação com a alienação do homem e a degradação do meio ambiente. Para tanto, inicialmente, cumpre tecermos algumas considerações sobre o fenômeno da alienação.

Alienação, originalmente, era um termo da psiquiatria utilizado para descrever uma forma de perturbação mental, como v. g. a esquizofrenia - uma perda de identidade pessoal ou de consciência, podendo ser definida como uma doença do $e u$ - o arrombamento do espírito, a anulação da personalidade individual.

$\mathrm{Na}$ dimensão econômico-social a alienação pode ser tida como a perda da consciência de si numa situação concreta, a perda da identidade e personalidade, da vontade individual, a coisificação do homem pela vontade de outros. 
A temática da alienação desperta no jovem Marx interesse de análise, sobretudo pela observação de seus efeitos no homem e a relação deste com seus semelhantes e com a natureza.

Tal tema - alienação - inicialmente é abordado por Marx (1993, p. 77-78) em sentido geral, como na análise da religião que para ele era "o sol ilusório em torno do qual se move o homem enquanto não se move em torno de si mesmo" ou “o ópio do povo". O sociólogo alemão acreditava que a religião servia como instrumento de conservação da alienação do homem comum da realidade e de si mesmo, utilizando-se aquela da ideologia para manter o poder e a dominação.

A alienação (Entaüsserung) foi objeto de crítica ${ }^{14}$ do "primeiro" Marx ${ }^{15}$, que realizou a análise deste fenômeno sob várias perspectivas, conforme se pode depreender da análise do quadro abaixo:

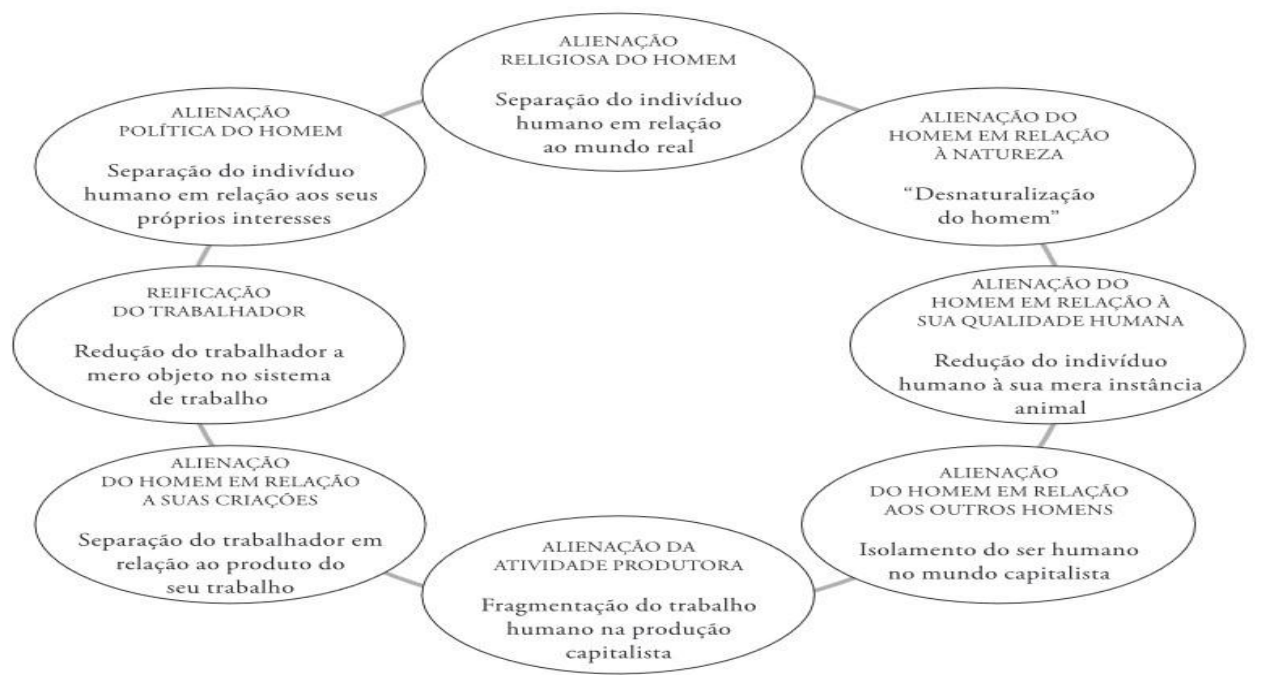

Figura 1: Formas de alienação discutidas pelo "primeiro" Marx.

A análise da alienação acompanhou a trajetória de Marx, seja de modo central ou lateral, na crítica à religião, à política, ao direito, à economia política e, como fundamental ponto de estudo, as relações de trabalho no sistema de produção capitalista.

Pela leitura das obras de Marx pode-se confundir como sinônimo de alienação o termo estranhamento (Entfrendumg). Entretanto, conforme esclarece Bello há diferenças tênues entre alienação e estranhamento que merecem atenção:

\footnotetext{
${ }^{14}$ Que em Grego (crinein) se reporta aos atos de separação e julgamento, buscando enriquecer a argumentação do que se pretende afirmar ou negar.

${ }^{15}$ Vide MARX, Karl. Manuscritos econômico-filosóficos e outros textos escolhidos. Tradução de José Carlos Bruni et al. $2^{a}$ ed. São Paulo: Abril Cultural, 1978, pp. 4-48.
} 
A alienação denota o ato de transferência, separação ou exteriorização das atividades sociais produtivas (o trabalho) do homem, resultante em uma objetivação ou coisificação; já estranhamento significa o distanciamento do homem perante este produto (objeto), do qual está separado e posto em situação de contradição ou oposição (Bello, 2013, p. 126).

Na obra $O$ Capital, primeiro capítulo, pode-se constatar o estudo de um dos muitos casos de alienação, na modalidade econômica - o "fetichismo da mercadoria" -, uma vez que tal fenômeno pode ocorrer nas mais diversas áreas sociais - como v. g. na política, na ideologia, etc.

A alienação para Marx corresponde à "reificação"16 para Lukács (1989) que traduz a idéia de, nas sociedades capitalistas, descrever a transformação dos humanos e suas relações em "coisas" ou "mercadorias" - a objetivação do indivíduo em objeto.

Tanto no processo de alienação pelo "fetichismo da mercadoria" quanto na "reificação" o que deve obter destaque é, na sociedade capitalista, o predomínio da coisa (objeto) sobre o sujeito (homem) e a dominação abstrata destes últimos por aquelas.

Conforme assiná-la Lukács (1989, p. 106), a atuação do capitalismo moderno consiste em "substituir por relações racionalmente reificadas as relações originais em que eram mais transparentes as relações humanas".

Nestas relações moldadas pelo sistema econômico capitalista e suas ferramentas, a sociedade se assemelha ao modelo empresarial mecanizado e racionalmente administrado, na qual a universalização da mercadoria e o destino do homem se inserem nas manobras da produção industrial moderna de coisas (mercadorias) e coisas (subjetividades).

Neste sentido, afirma Lukács (1989, p. 108):

Assim como o sistema capitalista se produz e reproduz economicamente a uma escala cada vez mais alargada, também, no decurso da evolução do capitalismo, a estrutura da reificação penetra cada vez mais profundamente, fatalmente, constitutivamente, na consciência dos homens.

Em que pese tais conceitos, principalmente os de Marx, terem sido desenvolvidos para compreender o modelo econômico capitalista de produção na "sociedade de produtores", em pleno século XXI são igualmente modernos para a análise das relações sócio-econômicas, sobretudo em tempos de economia capitalista globalizada, na qual o consumismo dá o tom das relações e serve como forma de alienação do homem e degradação do meio ambiente natural.

\footnotetext{
${ }^{16} \mathrm{O}$ estudo da reificação em Lukács tem como base a análise do fenômeno da alienação e do fetichismo da mercadoria, e provém do termo alemão Verdinglichung que guarda em sua tradução o sentido latino de res (coisa), que pode ser compreendido como coisificação.
} 
Nas sociedades contemporâneas, sobretudo as orientais que possuem o capitalismo moderno como modelo econômico, o consumismo tem um papel significativo ao criar vínculos culturais e subjetividades, bem como produzir relações políticas e sociais, se tornando não mais uma opção ou um direito, mas um dever do cidadão.

Apenas para tentar fazer uma breve distinção entre "sociedade de produtores" e “sociedade de consumidores", podemos referir que na primeira o sistema de produção capitalista se apropriava do corpo (potencial de trabalho) do operário, enquanto que na segunda chegou a vez de se apropriar de algo mais - do espírito do consumidor.

No modelo organizacional do capitalismo pautado na sociedade de consumidores as pressões coercitivas e o treinamento buscam atingir os indivíduos desde a infância, tornando-os consumidores cada vez mais insatisfeitos e vorazes.

Não poderia ser diferente, sobretudo numa sociedade em que tudo se tornou mercadoria, inclusive o self, na qual os símbolos (objetos) obscurecem as relações entre sujeitos.

Uma sociedade, de hiperconsumo, que funciona em constante desorganização psicológica - beirando a esquizofrenia -, na qual a quase totalidade dos aspectos da existência humana são invadidas pelas forças do mercado, que de um lado visa o prazer e o bem-estar individuais através do consumismo e, de outro coabita de forma opulenta com o subconsumo e os níveis alarmantes de desigualdade social e degradação do meio ambiente.

Dentro desta perspectiva de desigualdade na sociedade de consumidores Bauman (1999, pp. 102-119) descreve de forma metafórica as figuras dos "turistas" e "vagabundos". Sendo que aqueles se distinguem destes últimos pelo poder de consumo. Ambos são consumidores e indispensáveis um para o outro, mas o "turista" vive para consumir, está em constante movimento, exposto às tentações e a um estado de excitação que não tem fim. Já o "vagabundo" é um consumidor frustrado e almeja ser "turista".

Nesta linha de raciocínio ser "turista" e "vagabundo", na sociedade de consumidores, está relacionado a poder e opções de consumo, mas ambos são consumidores e possuem importância para o Capitalismo Mundial Integrado ${ }^{17}$, na condição de consumidores alienados.

\footnotetext{
${ }^{17}$ Conforme Guattari: "La consolidación y estabilización del capitalismo mundial integrado. Este nuevo tipo de capitalismo es el resultado de transformaciones y adaptaciones recíprocas entre el capitalismo monopolista y las diferentes formas de capitalismo de Estado. Integra, en el seno del sistema mundial, los diferentes componentes de las sociedades de clase y de castas basadas en la explotación y en la segregación social. Ramificados por todo el planeta, sus centros de decisión tienden a adquirir una relativa autonomía respecto a los intereses nacionales de las grandes potencias a construir una compleja red que no puede ser completamente localizada en un espacio
} 
$\mathrm{Na}$ lógica do Capitalismo Mundial Integrado, para ser é preciso ter e esta subjetividade é agenciada por uma poderosa operação midiática que produz modos de ser e de consumir, que modela os desejos, que prepara a subjetividade do indivíduo a partir de valores da hegemonia capitalista.

Valores estes que são inseridos na subjetividade individual e coletiva a partir de uma série de ferramentas coletivas apropriadas pelo suprapoder do Capitalismo - a escola, a igreja, a família, a mídia, os partidos políticos, as empresas, sindicatos, revistas, programas de televisão, etc.

$\mathrm{Na}$ atualidade o Capitalismo se apresenta com novas "garras" que alcançam a carne e o espírito humanos, bem como transformam o não-capitalizável em capital. E que tem razão de ser na necessidade do capital expandir suas áreas de domínio. ${ }^{18}$

Seja com que cara o capitalismo se apresentar - capital manufaturado, humano, financeiro, etc -, a natureza também passa a ser capital, negócio, valor econômico. E o consumo de produtos com apelo ecológico cria novas subjetividades no modo de ser e agir de indivíduos e coletividades, gerando lucro aos detentores do capital.

O "consumo verde" - consumo de produtos que carregam em suas marcas "selos" de ecologicamente e socialmente corretos, sustentáveis, etc - é negócio, pelo fato da cultura predominante ser capitalista e visar o lucro e não a preservação do meio ambiente para as presentes e futuras gerações.

E, como não poderia deixar de ser, as ferramentas midiáticas, dentre elas a publicidade em escala mundial, se incumbem de criar o consumidor verde - consumidor modelado pelo mercado.

Apenas para exemplificar, podemos referir aqui algumas empresas químicas erradicadas no Brasil que possuem selo de "ecologicamente corretas" e que por muito vem degradando o meio ambiente natural: Basf, Aracruz, Braskem. ${ }^{19}$

político delimitado -red de complejos energéticos, militar-industriales, etc... Su modo de intervención implica un reforzamiento constante del control reticular de los médios de comunicación de masas." (GUATTARI, 2004).

${ }^{18}$ No que se refere à necessidade do capital de buscar novas áreas de domínio, é de fundamental importância a noção de sobreacumulação e acumulação por espoliação que pode ser compreendida a partir da leitura de Harvey. Conforme o autor (p. 124): "O que a acumulação por espoliação faz é liberar um conjunto de ativos (incluindo força de trabalho) a custo muito baixo (e, em alguns casos, zero). O capital sobreacumulado pode apossar-se desses ativos e dar-lhes imediatamente um uso lucrativo. No caso da acumulação primitiva que Marx descreveu, isso significa tomar, digamos, a terra, cercá-la e expulsar a população residente para criar um proletariado sem terra, transferindo então a terra para a corrente principal privatizada da acumulação do capital. A privatização (da habitação social, das telecomunicações, do transporte, da água etc. na Inglaterra, por exemplo) tem aberto em anos recentes amplos campos a ser apropriados pelo capital sobreacumulado". (HARVEY, 2013, pp. 115-133).

${ }^{19}$ Informação disponível em: http://meumundosustentavel.com/noticias/20-empresas-sustentaveis/ . Consulta em $15 / 10 / 2014$. 
O objetivo final do capitalismo é o mesmo - o lucro. O capital se apresenta com novos contornos e dimensões e transforma quase tudo (inclusive homem e natureza) em bens de consumo.

Conforme salientam Hardt e Negri, dispondo sobre os mecanismos de controle à disposição do mercado e da criação de novas subjetividades:

As grandes potências industriais e financeiras produzem, desse modo, não apenas mercadorias, mas também subjetividades. Produzem subjetividades agenciais dentro do contexto biopolítico: produzem necessidades, relações sociais, corpos e mentes [...]. (2001, p. 51)

O consumismo está na ordem deste capitalismo de controle ${ }^{20}$ que, segundo Bauman é concebido num viés pós-moderno como Sociedade de Consumo, na qual criam-se demandas e mercados a partir do profundo conhecimento que as instituições disciplinares (empresas transnacionais, instituições financeiras, mídia e até Estados) possuem dos indivíduos.

Como já referimos em passagens anteriores, desde os primeiros anos da infâncias os indivíduos são adestrados a se tornarem consumidores conspícuos o que nos faz lembrar da estrofe de uma música da Banda Legião Urbana: "Quando nascemos fomos programados. A receber o que vocês. Nos empurraram com os enlatados dos USA, de 9 às 6.Desde pequenos nós comemos lixo. Comercial e industrial. Mas agora chegou nossa vez. Vamos cuspir de volta o lixo em cima de vocês".

O Capitalismo Mundial Integrado, por intermédio do controle exercido sobre a mídia e a publicidade, volta seu foco para as estruturas produtoras de subjetividades, símbolos e signos, manipulando as preferências de consumo, criando "necessidades", coisificando o homem e o meio ambiente.

E é neste mundo dominado pelo feitiço que o homem se aliena de sua essência e aliena o meio ambiente, como se este modelo de organização social pudesse se mostrar sustentável e que outros caminhos não pudessem ser trilhados. Será que temos escolha? Que atitudes podemos adotar para nos libertarmos destes grilhões que aprisionam não só nossos corpos, mas também nossas mentes?

${ }^{20}$ Gilles Deleuze, traduz a sociedade contemporânea como Sociedade de Controle. Diferente da Sociedade Disciplinar de Michel Foucaut que tem no capitalismo a disciplina voltada para a produção, a Sociedade de Controle - controle contínuo, simultâneo e descentralizado - é dirigida para o consumo (DELEUZE, 1992, pp. 219-226). 


\section{CONSIDERAÇÕES FINAIS}

A sociedade contemporânea, sobretudo as ocidentais, se divide entre aqueles que consomem de forma conspícua a natureza e os próprios homens e aqueles a que só resta o subconsumo. Tal fator gera uma desigualdade global, além da degradação do homem e do meio ambiente.

Se toda a população mundial consumisse recursos naturais nos padrões adotados pela população norte-americana, seriam necessários mais 3,5 planetas para suportar a capacidade de carga.

Em tempos de preocupação com os rumos do homem e dos impactos deste sobre o meio ambiente os níveis e produção e consumo atingem dimensões antes impensadas.

A sobreacumulação de capital faz com que novas áreas sejam objeto de mercantilização, dentre elas a subjetividade humana e a natureza. O "capitalismo verde" e o consumo de produtos ditos ecologicamente sustentáveis são exemplos desta nova roupagem vestida pelo capital.

As mudanças ocorridas no tecido social são acompanhadas (ou moldadas) pela metamorfose do capitalismo que, através de suas ferramentas atuam sobre a subjetividade humana, criando valores, sonhos, necessidades e tudo mais que o dinheiro possa comprar, como um feitiço sem antídoto. E assim as relações humanas são encobertas pela relação entre objetos - o corpo e espírito humanos se tornam objetos de consumo.

O capitalismo mundial integrado torna quase tudo mercadoria e cria nas subjetividades individual e coletiva a "necessidade" de consumir cada vez mais. Além das mercadorias tradicionais, os sonhos, a aceitação social, o bem-estar, a felicidade e os próprios sujeitos se tornam mercadorias.

Como afirma Bauman, estamos na hera da sociedade de consumidores, na qual tudo se tornou mercadoria - inclusive o self - e os símbolos obscurecem as relações entre sujeitos e estes são moldados ao consumo conspícuo. Consumir não se trata mais de um direito e sim de um dever social.

A hegemonia do capitalismo contemporâneo, se apropria de uma série de ferramentas - a escola, a religião, a mídia, as empresas -, para criar um exército fiel de consumidores manipulados, voltados ao consumo efêmero e endividados.

E diante deste cenário tanto homem quanto natureza se tornam ferramentas do capital, são alienados de sua essência. 
A emancipação parece estar longe de ocorrer, mas só com uma drástica quebra de paradigma nos padrões de produção e consumo o homem poderá se aproximar de sua essência para então buscar a proteção do meio ambiente natural, numa relação que possa se configurar como sustentável para ambos.

\section{REFERÊNCIAS}

BAUMAN, Zygmunt. Globalização: as conseqüências humanas. Trad. Marcus Penchel. Rio de Janeiro: Jorge Zahar Ed., 1999. . Modernidade líquida. Rio de Janeiro: Jorge Zahar Ed., 2001.

. Vida para consumo: a transformação das pessoas em mercadorias. Trad. Carlos Alberto Medeiros. Rio de Janeiro: Jorge Zahar Ed. 2008.

BELLO, Enzo. A cidadania na luta política dos movimentos sociais urbanos. Caxias do Sul, RS: Educs, 2013.

CAMPBELL, Coline. A ética romântica e o espírito do consumismo moderno. Rio de Janeiro: Rocco, 2001.

DELEUZE, Gilles, 1925-1995. Conversações. Trad. Peter Pál Pelbart. São Paulo: Ed. 34, 1992.

DUPAS, Gilberto. Economia global e exclusão social: pobreza, emprego, estado e o futuro do capitalismo. São Paulo: Paz e Terra, 1999.

FARIA, José Eduardo. O direito na economia globalizada. São Paulo: Malheiros, 1999.

FIORIN, José Luiz. Linguagem e ideologia. São Paulo: Ática, 1988.

GIDDENS, Anthony. As consequências da modernidade. Trad. Raul Fiker. São Paulo: UNESP. 1991.

GUATTARI, Félix. Plan sobre el planeta. La proliferación de los márgenes. Capítulo 1 del libro Plan sobre el planeta. Capitalismo mundial integrado y revoluciones moleculares. Madrid: Traficantes de sueños. Edición on-line: altediciones.com, 2004.

GONZÁLEZ REY, Fernando. Epistemologia Cualitativa y Subjetividad. São Paulo: Educ, 1997.

HARVEY, David. O novo imperialismo. Trad. Adail Sobral, Maria Stela Gonçalves. $7^{\text {a }}$ Ed. São Paulo: Edições Loyola, 2013.

HARDT, Michael; NEGRI, Antônio. Império. Rio de Janeiro: Record, 2001.

JAMESON, Fredric. Pós-modernismo: a lógica cultural do capitalismo tardio. São Paulo: Ática. 1996.

LACAN, Jacques. O Seminário, livro 4: a relação de objeto. Rio de Janeiro: Jorge Zahar Ed., 1995.

LUKÁCS, Georg. História e consciência de classe: estudos de dialética marxista. Trad. Telma Costa; Revisão Manuel A. Resende e Carlos Cruz - 2 Edição, Rio de Janeiro: Editora Elfos, 1989.

LUHMANN, Niklas. A realidade dos meios de comunicação. São Paulo: Paulus, 2005.

MARX, Karl. (1993), Introdução à crítica da filosofia do direito de Hegel. $1^{\text {a }}$ edição 1843. Lisboa, Edições 70. 
. Manuscritos econômico-filosóficos e outros textos escolhidos. Tradução de José Carlos Bruni et al. $2^{a}$ ed. São Paulo: Abril Cultural, 1978.

O capital: crítica da economia política: livro I; tradução de Reginaldo Sant'Anna. 19a Ed. Civilização Brasileira. Rio de Janeiro. 2002.

SIBILIA, Paula. O homem pós-orgânico: corpo, subjetividade e tecnologias digitais. Rio de Janeiro: Relume Dumará, 2002.

VEBLEN, Thorstein. A teoria da classe ociosa: um estudo econômico das instituições. Trad. Olívia Krähenbühl; apresentação de Maria Hermínia Tavares de Almeida. São Paulo: Abril Cultural, 1985.

WEBER, Max. Classe, estamento, partido. In: GERTH, Hans e MILLS, Wright (Org.). Max Weber Ensaios de sociologia. Rio de Janeiro: Zahar Editores, 1974. 